\title{
A second-take on the role of science: the case for applying public administration theory to natural resource management
}

\author{
Philippa M. Brock ${ }^{1,2^{*}}$ (D) and Daniel K. Y. Tan ${ }^{2}$
}

\begin{abstract}
Background: Natural resource management theory has been informed by disciplines such as ecology, agricultural science, economics and engineering; but much less so by the literature of planning and public administration. This paper demonstrates that applying an incremental view to what is traditionally seen as a rational-comprehensive discipline provides insights into resource management theory and practice, including adaptive management.

Results: We show how current theory and practice in natural resource management are not aligned to the degree that is routinely presumed. In particular, the prevailing focus on optimality creates conflicts, especially during democratic decision-making, whereas adopting a participatory-incremental hybrid approach should provide a superior solution, which is discussed here in the context of Life Cycle Assessment by resource managers.

Conclusion: Resource management tends to be both incremental and participatory; and whilst decisions are strongly informed by science, on reflection, the process of formulating decisions is rarely rational-comprehensive. We suggest greater retrospective analysis of resource management decisions at a theoretical level. This may result in adoption of a theoretical framework which better supports practice, a reduction in tensions between those trained in the arts and sciences; and more 'freedom' in practice, through a softening of the focus on optimality.
\end{abstract}

Keywords: Natural resource management, Planning theory, Public administration, Life cycle assessment, Incremental decision-making, Adaptive management

\section{Plain English summary}

During the 1980s, some progress was made in applying planning theory to other disciplines. The incremental decision-making model was applied to the evaluation profession and to the scientific research and development process but not to natural resource management per se. Most notably, in the late 1980's planning theory was applied to the medical and atomical sciences. More recently, new theoretical approaches have been developed for natural resource management which combine rationalcomprehensive characteristics with a step-wise approach.

In our manuscript, we strive to advance resource management theory by applying the spectrum of approaches

\footnotetext{
*Correspondence: pip.brock@dpi.nsw.gov.au

${ }^{1}$ Port Stephens Fisheries Institute, Department of Primary Industries, Locked Bag 1, Nelson Bay, NSW 2315, Australia

${ }^{2}$ Sydney Institute of Agriculture, School of Life and Environmental Sciences, Faculty of Science, The University of Sydney, Sydney, NSW 2006, Australia
}

from planning and public administration. We show how resource management may be an incremental-participatory hybrid. Whilst decisions are strongly informed by science, on reflection, the process of formulating decisions is rarely rational-comprehensive. We use Life Cycle Assessment (LCA), as applied to climate mitigation in the agricultural sector, to illustrate the theoretical opportunities. We also elaborate on the nature of adaptive management in an attempt to stimulate debate which will underpin advances in theory, enabling support for practice.

\section{Background \\ Introduction}

The purpose of this paper is to demonstrate some of the shortcomings of resource management theory and the consequent discrepancy between theory and practice. We elucidate these shortcomings by drawing theory from planning and public administration literature. In doing so, we strive to develop theory that reduces, or at 
least provides a better understanding of, tensions arising during decision-making. We are confident that applying planning theory to resource management will be beneficial because significant theoretical advances have already been achieved in other disciplines when planning theory was similarly applied to the medical and atomic sciences [15] and the profession of evaluation [20]. However, because this paper relies on terminology drawn from two distinct and relatively unrelated disciplines, there is merit in digressing to clarify terminology, before proceeding further.

Natural resource management is about taking actions to produce commodities within a context of sustainability. Natural resource managers encompass all who are concerned with the supply of, or access to, the natural resources upon which societies rely for their survival and development [21]. This area of work is broad and draws together practitioners from diverse disciplines, mostly with a rational-comprehensive mindset, into what can loosely be described as the resource management profession. In contrast, planners focus on optimising location, time and place for people [42, 51], with an emphasis on managing change in land use. Over time, the focus has shifted from being centred on control, to include elements of participation [31] and foresight [37, 47]. Planning theory draws considerably from public administration literature and, as such, we refer to planning and public administration theory as 'planning theory'. Planners form a more discrete profession than resource managers. However, the differences in cohesion and scope do not prevent cross-disciplinary learning.

Part of the distinction between planning and resource management theory is the extent to which the respective theoretical frameworks manage the 'problems of science' [13], namely the difficulties associated with the scale of scientific problems, the ability to test only predetermined hypotheses, and the absence of 'perfect knowledge'. Resource managers partly acknowledge the 'problems of science' but mostly at a practical level, which is evident through an emphasis on the development of increasingly sophisticated tools and techniques. They describe their profession in rational-comprehensive terms, seeking to optimise outcomes primarily from the perspective of the biophysical sciences. Like resource management, planning is also hard to define, but planners have developed a deeper fundamental theoretical basis that is reflective, and which underpins and supports, rather than directs practice [59]. It is not our intent to imply that resource management is not a supportive process, rather that it does not have the support of a deep and reflective theoretical basis to the same extent as planning, leading to greater emphasis on 'how to' tools and techniques to support practitioners. The theoretical basis of planning encompasses a spectrum of decision-making approaches from rational-comprehensive to participatory and incremental [12, 37, 44].
We define rational-comprehensive (or synoptic) planning as striving to assess and compare all possible solutions to problems, based on science, and working towards a pre-determined optimum. There is sometimes a misconception amongst resource managers, brought about by differences in professional language, that when adoption of models other than those which are 'rationalcomprehensive' is suggested, that this equates to suggesting an 'irrational' or less valid approach. Planners do not see 'rational-comprehensive' and 'irrational' as antonyms. We define incremental decision-making as being about a step-wise progression that meets the interests of those affected by a decision, without concern for a predetermined optimum but often based on rational data. The incremental approach acknowledges 'bounded rationality' [44] and constraints brought about by the situational context, cognitive limits [30] and inherent inadequacies of the decision-maker $([22,45])$. Many resource managers mistakenly believe that incremental decision-making is slow, but this is often not the case, with planning literature illustrating how a rapid sequence of small changes can go unnoticed [43, 45]. This misconception about the speed of change is especially evident in recent resource management literature that espouses the benefits of 'transformational' change, when a theoretical framework built on a step-wise progression would more than adequately meet the desired objectives [55], and also avoid the risker elements that are involved in transformation. In fact, already well-developed planning theory that critiques 'radical' approaches would shed light on the nature of transformational change and the allied 'resilience' theory, which describes how the level of resilience determines the ease with which a system can move to a less or more preferred state. A resilient system tends to resist natural pressures to move to a less preferred state but can also resist the effects of large-scale management intervention, even those that attempt to be 'radical'. As incremental decision-making is not based on a pre-determined optimum, the rate of change (in environmental condition or public opinion) is not a prominent consideration in planning theory. Two forms of incrementalism are evident, firstly, where decisions are based on previous decisions as new knowledge comes to light or as biophysical, economic, social or political circumstances change and, secondly, where the experience, knowledge-base and opinion of the decisionmaker changes incrementally.

Participatory approaches, include democratic process and consensus, are at the incremental end of the planning spectrum [19]. Some other approaches that provide insights into the way in which resource management is sometimes conducted and which are also at this end of the spectrum include 'advocacy' and 'mixed scanning' [22]. The former involves deliberate representation in 
decision-making on behalf of the environment or for people less able to express their views. The latter involves iterative collection of information. However, for the purpose of this paper, it is sufficient for resource managers to understand that planning theory contains a spectrum from rational-comprehensive to incremental approaches, with a participatory incremental hybrid model [3] also acknowledged.

Now we return to the problem at hand, namely, addressing the constrained nature of resource management theory and showing what the aforementioned spectrum of approaches offers in terms of shedding light on the fundamental nature of resource management. We strongly critique resource management with the intent of improving our own profession.

Natural resource managers tend to be trained in disciplines such as ecology, agricultural science, forestry, hydrology, soil science, economics and engineering, but tensions arise because they are required to balance economic, social and environmental outcomes, often with different contextual goals and within a participatory and democratic context. Resource management policy and legislation play an important role in managing these tensions, whereas planning legislation tends to be effectsbased, rather than prescriptive. This opens opportunity for 'creativity', such as in the design of new spaces, with many planners trained in architecture and creative design. However, because planning problems tend to occur on a 'smaller canvas', at a practical level planners sometimes adopt routine processes, such as for development assessment. This does not preclude them from 'creativity' when conducting design-related tasks. Resource management legislation, policy and regulations protect, guide and sometimes direct decision-makers, some of whom live in the communities affected by their own decisions. Although some enhancement of fundamental resource management theory has occurred [53], it remains somewhat constrained by the rational-comprehensive origins of the traditional fields on which resource management is founded and consequently provides suboptimal guidance for practitioners.

A few authors have attempted to introduce theoretical elements from planning theory to resource management. For example, implications for threatened species management legislation were analysed in the context of planning theory [12] and a step-wise progression was discussed in a water management context in The Netherlands [29]. More recently, during a critique of transformational change, myths about incrementalism were dispelled and support provided for the concept of continuous change [55]. The improved understanding about the nature of incrementalism that this critique provided was a key step forward because the false assumption that incremental change is slow has hampered the integration of incrementalism into resource management theory. Also, discussion in resource management literature about participatory techniques, such as Participatory Rural Appraisal (PRA) [1, 41] and semistructured interviews $[5,6]$ are at the fringe of theoretical cross-fertilisation between the professions. Even though these participatory techniques are mostly applied with the intent of optimising decisions, rather than supporting incremental change, the body of literature surrounding these techniques provides a place where theory about incrementalism could be introduced, because participatory approaches are compatible with and at the incremental end of the planning spectrum.

The large scale and complexity of environmental problems is often used as an argument for the need for robust rational-comprehensive approaches. However, Chalmers [13] recognised the difficulties in addressing large-scale multifaceted issues as one of the 'problems of science', a difficulty which is not only faced in the biophysical sciences but also in the social sciences during democratic decision-making. On reflection, where genuine participatory approaches have been applied to complex environmental problems, this has proved beneficial. Participatory approaches often bring together views of local community members with those of different perspectives, including those of the international community through Non-Government Organisations and treaties with other countries. This was evident in social and participatory decision-making in an environmental context during the development of Land and Water Management Plans in New South Wales, Australia (e.g. [4]), where both community and government stakeholders internalised scientific knowledge and prior management experience to develop decisions that they deemed suitable and realistic at that point in time, with awareness that optimality differs depending on the perspective of individuals. Community involvement in decision-making has now become a 'mainstream' component to water management in Australia, particularly for the Murray-Darling Basin [2]. The merit of partly deferring to those with knowledge about the outcomes of past management actions, rather than placing exaggerated reliance on increasingly complex research such as through systems modelling, is evident. Einstein has been attributed as saying that 'The only source of knowledge is experience', which points towards a human dimension in decision-making and the value of incremental improvement in the knowledge-base of practitioners.

What planning theory offers resource management is a deeper understanding about the limitations of many types of decision-making frameworks. Planning theory provides debate about both 'the problems of science' [13] and the 'imperfect nature' of political and democratic decision-making [44]. Additionally, the way in 
which planners continue to evolve their theoretical basis in what was originally described as a reflective manner [25], provides an approach that resource managers could benefit from by adopting in their own practice. Planning theory continues to evolve, with recent debate explicitly tracking how the traditional role of the 'planner as technician' remained appealing, despite a waning of emphasis on a rational-comprehensive approach by theorists [58]. This retrospective analysis of decisionmaking by planners enables theory to be continually updated to align with practice. In contrast, resource managers tend to develop improved tools and techniques in an attempt to match practice to existing theory, rather than update theory based on analysis of the nature of past decisions [52].

We now delve into retrospective analysis and apply planning theory to resource management, to provide insights into real-world resource management theory and practice. We consider Life Cycle Assessment (LCA) and subsequently discuss the application of adaptive management and its parallels with LCA guidance. LCA is a systematic approach to understanding the environmental consequences of producing units of specific commodities, through supply chain evaluation. LCA was chosen because this field of work is currently seeking theoretical guidance, with discussion by LCA practitioners about roles and guiding principles deepening over the past 4 to 5 years, to discussion about the role of market failure, the scale of environmental problems and the realities of fast incremental improvement. Even though LCA is not a mainstream area of work within Australia, its use globally is increasing and it provides a discrete example which is strongly indicative of the broader resource management profession. For example, LCA faces practical tensions associated with optimizing use of large data sets and achieving application of research to inform policy. Also, tensions are increasing at a practical level as social and economic LCAs are being merged with environmental LCAs [57].

In contrast, adaptive management is a broader framework, which has been applied by resource managers for a decade longer than LCA. This approach is underpinned by the precautionary principle, whereby a lack of certainty should not be used as an excuse to avoid action which might prevent environmental impact. Adaptive management has been chosen here because it illustrates the problems arising from the constrained theoretical base of resource management. Practitioners view adaptive management as a means of overcoming the 'problems of science', given problems of geographic and temporal scale and imperfect knowledge. However, on reflection, this approach is rational-comprehensive in intent, as it is about 'experimenting on the problem' and expanding the experiment to the system as a whole.
Even though the resultant decisions are incrementally different to previous decisions, an incremental form of change is viewed as less robust and an underlying assumption remains that optimality can be predetermined. The intent of adaptive management is not consistent with, and in fact masks, the classic form of incrementalism defined and accepted by planners; and which is characteristic of resource management decisions when analysed reflectively.

\section{About life cycle assessment}

LCA is a structured, comprehensive and internationallyrecognised method used to evaluate the effects of producing goods and services, and is guided by ISO standards $[23,38]$. The approach was developed for the manufacturing sector and has been applied to the agricultural sector during the previous 20 years, or so [36]. LCA has been used to evaluate the environmental impact of producing a wide array of food and fibre commodities, such as wheat $[7,10]$, wool [9], rice [54] and cotton $([32,34])$. Whilst LCAs are intended to be 'cradle-to-grave' [17, 28], many agricultural studies are conducted by practitioners with expertise and an interest in determining the relative effect of on-farm management change options with some degree of certainty and, as such, comparative 'cradle-to-farm gate' studies are common. One advantage of LCA is that it assists to avoid 'burden shifting' whereby a reduction in one form of impact (such as global warming) might be offset by another form of impact (such as eutrophication), locally or globally. The profession has tended to focus on assessing global warming impacts, given the availability of many methods to assess implications for other impact categories [36]. However, integration across all biophysical impact categories is increasing.

Having described the purpose of LCA, we now summarise theoretical development surrounding LCA. Early theoretical development involved preparation of practical guidance documents, to optimise decision-making and included books (e.g. [17, 36]), journal papers about methods, governing ISO standards $(14,040$ and 140,044$)$ [23], tools (e.g. SimaPro, GaBi) and databases (e.g. Ecoinvent). Subsequently, LCA practitioners have begun to discuss deeper problems, including those surrounding market failure [11], variability in the natural assets [27], the scale of environmental problems, data availability and requirements $[46,57]$, the multi-stakeholder nature of problems and realities about fast incremental improvement [39]. In fact, Bo Weidema (Executive Manager of the LCA Ecoinvent database and President of the International Life Cycle Academy) spoke at the AgriFood LCA conference in Dublin in October 2016 about current practice being limited because of a lack of completeness in knowledge and limited use of all impact 
categories; constraints affecting use of consequential analysis; reduced ability to nowcast and forecast; and low levels of transparency about data quality and spatial applicability. Discussion by practitioners has also included phrases, such as 'people acting on the data that they have', 'willful ignorance', 'biases because practitioners often do not carry the cost of the decision', 'designing a winning strategy' and the 'role of government in establishing a level playing field'. In fact, diversification of the profession into social and economic assessment is bringing together practitioners with broader skillsets and therefore more diverse fundamental training about the role of science, creating tensions. Many of these problems are not unique to LCA and are commonly faced by resource managers.

\section{Methods}

\section{Application of planning theory to LCA}

To illustrate the way in which planning theory can inform LCA practitioners about the approach that they take to their profession, we explore two key problems faced by LCA practitioners. These insights are then applied to resource management more generally. In doing so, this provides reflective evidence about the nature of resource management theory and practice. The first problem is that of allocating environmental burdens within a production system in the context of market uncertainty. To effectively inform decision-making, it is necessary to allocate burdens between co-products within a multifunctional production system, such as between cotton lint and seed [33], between wool, skins and meat [9] and between milk, meat, calves, manure and hides [24]. A second problem for practitioners is that of accurately identifying where large-scale changes might occur in linked production systems. As the LCA process requires a global mass balance in production to be maintained, a decision to introduce legumes into a cereal cropping rotation, for example, could drive a series of changes in background systems. The increase in quantity of legume produced, the co-production of biologicallyfixed nitrogen and the reduction in cereal production within the system could potentially drive global changes in land clearing, land use and fertiliser production. Displacement of cereals by legumes may even alter greenhouse gas emissions by changing the rate of carbon sequestration, given that legumes produce less biomass than cereals due to the carbon cost of $\mathrm{N}$-fixation ([35]; Brock 2016a, b).

To address the first problem, that of allocating burdens between co-products, LCA practitioners have developed hierarchical guidance, whereby system expansion is the preferred approach, with the system subdivided into sub-processes, with each commodity studied separately $[17,23]$. This approach is most easily applied where product components can be easily separated, such as in car manufacture. However, where separation of components is difficult and uncertain, product substitution is deemed acceptable. In the case of wool production systems, the environmental burden for substitute co-products, such as beef or chicken meat to account for lamb and mutton production, can be subtracted, with the remaining burden allocated to wool production. Less preferred approaches include biophysical and economic allocation, with biophysical allocation potentially involving comparison on the basis of protein and energy content. Changes to enterprise characteristics, such as from wool to meat dominance, through genetic selection add to the complexity of the allocation process [9].

To address the second problem, that of understanding large-scale changes in background systems, LCA practitioners have moved increasingly towards a consequential approach, whereby all global interactions are internalised within the assessment. The problem with this approach, in practice, has been a tendency to make substitutions by applying global average impact values and sometimes the knowledge of market forces on which the assessment is based, is limited. A false impression of accuracy is sometimes created through this focus on inclusivity, with transparency often lost. On face value, from a resource manager's perspective, in the case of introducing a legume into a cropping rotation, it would be best to include all of the abovementioned interactions in a complex systems model. LCA guidance even provides a process for rating the certainty and reliability of data that might be included in such an approach.

However, in doing so, visibility of the complex interactions is lost from the decision-maker. In this case, one plausible scenario is that the additional quantity of legume produced locally could be directly offset by a reduction in legume production in another country. A reverse offset in cereal production may then occur. In fact, as the substitution is likely to be between similar grades of wheat quality, it is likely to occur on the same class of land at a similar yield, resulting in limited net change. The expectation within LCA guidance is that consequential LCA would be conducted, with a focus on drawing on data about the global grain pool where production arises from an array of land classes. In practice, this may be misleading and a deliberate choice to explain potential consequences qualitatively, rather than internalising them quantitatively in a LCA, may be more desirable. Also, as Australia's wheat production is only $1-3 \%$ of global wheat production, within the global wheat pool, offsets may be limited in the short term and are difficult to track with certainty across an array of commodities, such as rice, soybean or canola, to equalize global energy and protein production. Systems may even 
be intensified or product characteristics (e.g. protein content) altered through changes in fertiliser use or manipulation during the manufacture of products, such as pasta and bread, in which case, it is necessary to account for the change in inputs and processes. The focus of this paper is not on the relative merits of consequential LCA, rather on developing fundamental theory which underpins future guidance, when faced with uncertainty.

\section{Results}

So, how would planners view guidance about the first problem, that of how to allocate emissions between coproducts? They would see this guidance as being mostly about 'how to' conduct practice from a 'tools and techniques' perspective, rather than providing a deeper theoretical underpinning (Table 1, items 1 and 2). They would also see it as highly prescriptive, when theory that supports planning has moved from prescriptive to 'effects-based' and participatory approaches (Table 1, item 7). Note that an 'effects-based' approach is a deeper concept than the practical function of 'impact assessment', in which both resource managers and planners are employed. Resource managers also conduct participatory decision-making [48] and a few are skilled in the social sciences but the inclusion of participatory approaches tends to be underpinned by a focus on optimality, rather than from a democratic perspective. Even discussion about 'neat' rather than 'net' gain tends to be concerned with optimality, rather than due process, perhaps without a full understanding of the theoretical origins to this difference in emphasis. A planner would be more interested in providing the results of multiple allocation scenarios to specific stakeholders involved in implementing change, in a participatory sense, rather attempting to achieve precision and striving towards optimality (Table 1 , item 5). They would see consultation conducted by resource managers as somewhat tokenistic, given the tensions with scientific approaches (Table 1, item 11). The attempt to internalise all parameters within the assessment process and expand the system to overcome the 'problems of science' demonstrates the rationalcomprehensive intent of LCA guidance [13]. This provides some evidence, that at least from an LCA perspective, resource managers strive towards optimality and attempt to develop an 'all encompassing' solution, supported by tools and techniques; when on reflection, decisions about impact assessment tend to be a debate which weighs up multiple assumptions to achieve an incremental difference. Parallels are evident in water management, with modelling approaches and continuous adjustment of decisions in a participatory manner [2]. Even expert panels are often separated from the process of informing citizens. A planner would acknowledge that a predetermined optimum is rarely able to be articulated, let alone achieved and that the scientific processes has as many limitations as a democratic political process (Table 1, items 6 and 13), given 'current situational demands' and the presence of 'unofficial goals' [20].

In terms of managing the global consequences of production, a planner would view market substitutions as rarely certain and often multi-dimensional; and would be concerned that because a consequential LCA is seen to be complete, that any omission may be more easily overlooked. The need to optimise the application of science whilst not 'overstepping the mark' in terms of modelling assumptions, parallels discussion by Termeer et al. [55] about the potential for 'unrealistic ambition'. Resource management has been strong on the development of tools and techniques, such as LCA and its multi-faceted consequential approaches and this has reduced their need to rely on professional judgement. However like planners, resource managers will resort to professional judgement when needed. The theoretical support for resource managers to do so is not strong, whereas planning theory has described the 'role of experience in informing decisions' [20], which has opened the opportunity for creativity in decision-making (Table 1 , item 10). As the planning profession tends to be flexible [58], except when conducting routine assessments on a particularly 'small canvas' and this has created a requirement for the profession to be well defined. In contrast, resource managers continue to grapple with their role in bringing together different professionals that can inform the application of market flows in decisionmaking (Table 1, item 9) and tend to seek support, through regulations for larger decisions. A planner would be unlikely to evaluate the outcome of a specific consequential LCA, instead focusing on evaluating implementation against plans, whereas resource managers are very interested in establishing a 'perfect plan' and evaluating the outcome of specific decisions that it has informed (Table 1, item 12). In fact, early LCAs were primarily case-specific and evaluated the effect of management options which had been identified elsewhere or for related purposes. Environmental Product Declarations, which are often based on LCAs also require case-specific evaluation against minimum standards. This difference may be due to planners being supported by a legislative basis, which has gained strength from retrospective fundamental theoretical development, whereas resource managers rely on practical tools and regulations to support them in practice and to indicate underlying ethic and intent (Table 1, item 4). Whilst planners tend to be less concerned about issues facing rural areas, they have discussed the complex nature of resource management problems (Table 1, item 14). As such, when considering global product substitutions, planners would require multiple scenarios, to understand 
Table 1 Contrasts between the NRM and planning professions to aid in ongoing cross-fertilization

Resource management
1. Theoretical development about NRM has been weak on approaches
but strong on practice.
2. The nature of NRM, its ethic and intent are not clear at a theoretical
level.
3. In NRM environmental and economic objectives tend to be more
important than social objectives; and a conflict remains between
environmental and economic objectives.
4. NRM policy and legislation defines practice in states and provides
some indication of the underlying ethic and the approaches taken.
some indication of the underlying ethic and the approaches taken.

5. Resource management takes a rational and participatory approach, but has not debated the spectrum from rational to incremental approaches. It can be described as a participatory form of incrementalism.I

6. Theory about participation in resource management is limited and apparent conflict between rational and participatory approaches remains.

7. In resource management decision-making has tended to be more about process, whereas implementation has tended to be more about outcomes.

8. Adaptive management characterises the approach of resource management. Whilst it takes a rational and sometimes also a participatory approach, it is actually incremental in outcome.

9. The role of the resource manager is not clear, even though theory about resource management tends to be about practice. Theoretical development tends to be within rather than across professions and tends to be about case studies.

10. Resource managers have developed, discussed and adopted empirical and participatory techniques and have tended to apply them to improve rational decision-making. So, creativity and the design of solutions tends not to be valued.

11. Despite an emphasis on rationality in resource management, the use of participatory approaches and information about social issues has increased. However, consultation is sometimes tokenistic.

12. Resource managers spend most of their time developing and implementing plans and to some extent conducting evaluation. The emphasis on evaluation is strong and it is often conducted on a case-bycase basis.

13. Resource managers have rarely debated the role of politics, which they tend to view as an influence on rational decision-making, instead of a way of making decisions.

14. Resource managers often conduct management in rural areas and address management issues facing these areas. They have recognised the complex nature of these issues.

\section{Planning}

Planning theory is about explaining approaches to decision-making, but is weak on practice.

The nature of planning, its ethic and intent are relatively clear, because theoretical development has been substantial.

In planning social and economic objectives tend to be more important than environmental objectives; and planning theory has addressed the influence of these objectives.

Planning is supported by a legislative base which enables a range of approaches, including negotiation. This base is supported by planning theory.

The spectrum from rational to incremental approaches to planning has been debated and planning has been placed at the incremental end, without rejecting rationalism.

Planning theory has discussed the adoption of public participation, partly through participatory environmentalism. Participation has been described as part of the solution to dispute.

In planning, decision-making has moved from a prescriptive approach to negotiation. Implementation tends to be conducted through prescriptive development assessment.

Adaptive management has not been adopted by planning. However, Planning theory, especially about incrementalism and contingencies, sheds light on the nature of adaptive management.

The role of the Planner is in one sense better defined, because of the substantial theoretical development, despite the difficulty in defining planning and the interdisciplinary nature of the profession.

Planners have developed, discussed and adopted fewer empirical and participatory techniques, relying more on professional judgement, which allows for creativity and the design of solutions.

The use of participatory approaches in planning has increased. However, its use has tended to be less open. As planning has become more about negotiation, advocacy has increased.

A greater number of planners spend their time assessing developments against plans, rather than evaluating plans. Planners rarely evaluate the outcomes of specific plans.

Planners have discussed politics, which they tend to view as a method of decision-making, a method which is compatible with incrementalism.

Planning occurs less often in rural areas but is being extended. When it does occur in rural areas, it tends to be to manage future development, rather than to solve physical problems. However, Planners have discussed the complex nature of environmental issues.

the range of possibilities, which they would consider as new information comes to light and circumstances change. A planner would see the transparency provided by a series of attributional or partial consequential LCAs, as a tradeoff with completeness; and see LCA as a tool, rather than providing the decision per se.

Upskilling decision-makers and presenting alternative scenarios, as a planner would prefer, would be seen by a LCA practitioner as less robust than developing an integrated LCA; or as a failure or flaw in modelling capability, with the term 'willful ignorance' having been applied. Plevin [50] who generally supports consequential LCA describes how 'even the best practical consequential LCAs cannot produce definitive quantitative estimates of actual environmental outcomes', echoing Chalmers [13]. A planner would view the approach of providing less complex multiple scenarios more rapidly as a means of being flexible and nimble in decision-making. The perceived need to develop perfect knowledge about commodity markets and political and social contexts has let to discussion in the LCA community, not only about fluxes within current markets but as to whether markets themselves are expanding. In addition to the problem of food waste, some LCA practitioners support a view that 
global food security tends to be about food distribution [39], driven by country-specific power differences [56], rather than the need for additional production; whereas others do not hold this view. Ingram [38] describes how past endeavours were about increasing production levels, with emphasis on agronomy and to some extent livestock and fisheries expertise. The emphasis then changed to reducing environmental cost; and then to meeting dietary needs and food preferences more so than increasing the volume of production; with an emphasis on social and political aspects of decision-making.

By applying the spectrum of approaches from rationalcomprehensive to participatory and incremental, it is evident that whilst decisions informed by LCA have a strong scientific basis, decision-making per se has some key incremental features. By relaxing the emphasis on optimality and instead focusing on robust and transparent information provision, there may also be a greater acceptance of the need to develop social LCAs alongside, rather than embedded in environmental LCAs, or to even use different strategies for social and economic assessment. Resource managers have tended to focus on environmental and economic objectives, whereas planners have tended to focus on social and economic objectives (Table 1, item 3), therefore developing expertise in participatory and democratic decision-making. Even though some resource managers have expertise in social science [48] they could benefit from wider adoption of the expertise developed by planners, especially about democratic process. In fact, planning theory paves the way not only for decision-makers to incrementally adjust their views but also for the LCA profession to encounter incremental improvement in its own theoretical and practical knowledge base. Before we turn to the question about how resource managers can optimise their application of learnings from the planning profession, we discuss the characteristics of adaptive management.

\section{The role of adaptive management and parallels with LCA guidance}

So how would a planner view adaptive management? Adaptive management has been developed to overcome the problems of science, especially around the large scale of environmental problems. Adaptive management is based on the premise that an optimum exists, even if difficult to attain, and experimentation on the problem itself is supported (Table 1, item 8). It differs in intent from the step-wise approach of incrementalism, which is about participants in a decision-making process adjusting their views in changing economic and political contexts to develop shared objectives for a point in time. However, on reflection, most resource management decisions, including those where adaptive management has been applied, tend to be incremental in outcome. The difference in intent and outcome create theoretical conflict. The recognition of the large scale of many resource management problems and the complexity of both small and large scale problems, has led to the development of tools and modelling approaches, with an emphasis on monitoring progress towards a perceived optimum [18, 26], which is often rarely achieved. The recent emphasis on 'big data' and expanded capacity to manage large datasets has resulted in resurgence in optimism about the ability to model entire systems and identify and achieve optimality. This optimism also amplifies tensions between rational comprehensive and participatory and democratic approaches.

Whilst adaptive management is a valuable tool, it has masked the ability for resource managers to consider adopting incrementalism in its classical sense. On reflection, ongoing improvement in practice could be seen as incremental and participatory, perhaps an incrementalparticipatory hybrid, with the support of science to inform actors and develop policy scenarios. LCA and adaptive management have many similar characteristics, both placing preference on expanding the problem to consider the system as a whole and identifying all potential consequences. However, LCA tends to place emphasis on its ability to forecast impact, with its 'skill' derived from data about the degree of impact or 'pressure', whereas adaptive management tends to take a retrospective analysis approach, prior to conducting forecasting, as it contains elements that concern not only the 'pressure' but also the resultant environmental 'state' and 'response'. A greater recognition of the spectrum of approaches will shed light on the tensions that arise between what is promoted as best practice and the nature of decisions that have been formulated in the past, not only in the context of LCA and adaptive management but also for the resource management profession as a whole.

\section{Discussion}

The way forward for NRM

We contend that benefits will arise from practical and theoretical disciplinary cross-fertilisation. A practical approach by Haasnoot et al. [29] in developing Dynamic Adaptive Policy Pathways shed light on the role of 'optimality' and the need to deviate from static 'robust' plans. Also, deeper retrospective analysis conducted by Collingridge [15], when introducing incrementalism to the medical and atomic sciences, provides for understanding of theoretical differences, without proposing a specific method or framework, as a resource manager may be inclined to do. These two approaches will need to occur concurrently, to ensure that deeper theoretical differences are not overlooked as specific techniques are developed. The deeper theoretical approach of Collingridge [15], which is foremost in this paper, will need to be 
progressed cautiously to ensure that misunderstandings and conflict do not result, given the difficulty of drawing together two different and somewhat competing disciplines.

In short, we offer a word of warning about rapid or forced integration between the professions; and instead propose cross-fertilisation, through which they learn from one another. Several false starts through practical attempts at integration have occurred. At a local level, in New South Wales, two government agencies were merged to form the Department of Infrastructure, Planning and Natural Resources without full consideration of the differing fundamental training of practitioners in the former planning and natural resource focused departments. The merger was short lived (2004-2005), despite advice being taken by senior staff about the underlying nature of differing approaches and cultures (Adrian Harte, pers. comm). Also, there is a risk of misunderstanding of terminology. John Ingram (Oxford) spoke at the AgriFood LCA conference in Dublin in October 2016 about the UNEP International Resource Panel and development of 'resource-smart food systems'. He described the role of behavioural economics and how change will be through 'incremental improvement' and 'iterative' but that it 'will need to be fast', indicating that 'no step changes are going to happen'. As planning theory has not been widely adopted by resource managers, this terminology, whilst well understood by the presenter and providing highly relevant insights, would have seemed to be conflicting for some practitioners.

One of the first steps for either practical or theoretical cross-fertilisation is for resource managers to better understand the intent of their current tools, techniques and theories (Fig. 1) and where resultant decisions could best be classified on the spectrum of decision-making approaches. As part of this process, it would be beneficial to develop a greater theoretical understanding of all decision-making approaches, not only rationalcomprehensive, incremental and participatory but also contingency planning, advocacy, consensual and even radical approaches; potentially drawing insights from economic theory. It is the difference in extent of theoretical development and understanding of respective language and concepts, which makes cross-fertilisation the most difficult. It also hampers the task of describing the merits of cross-fertilisation. In fact, the differing levels of theoretical development and tendency for limited reflective analysis by resource managers was evident when seeking additional evidence to support this paper. We have added to this limited reflective examples by analysing our own experiences (Table 1). Planners have been able to develop a strong fundamental theoretical basis through retrospective analysis, rarely providing fully-evaluated case-studies, instead by drawing on experience to develop concepts, which they place in literature for critique by others. However, there is merit in continuing to develop case-studies that not only critique intent and purpose but also reflectively understand the deep fundamental nature of procedural outcomes, to build new theory.

At a practical level, opportunities include:

1. Acknowledging that incremental change can be rapid;

2. 'Letting go' of the need for a pre-determined optimum;

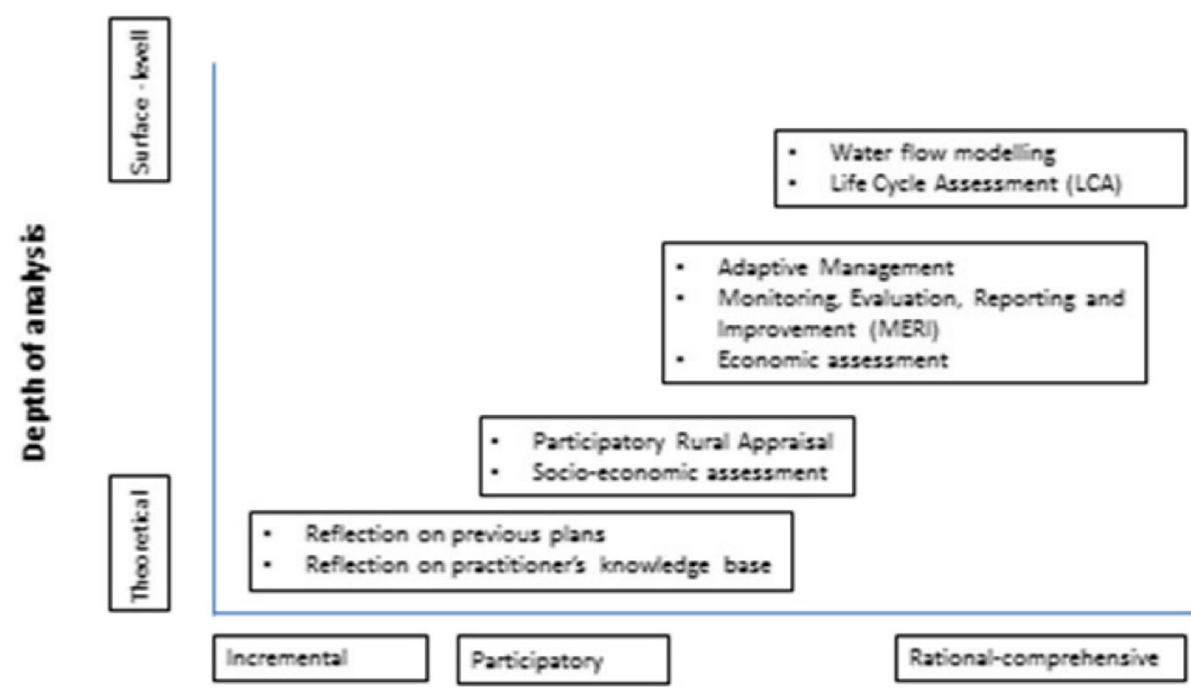

Decision-making spectrum

Fig. 1 Conceptualising a new paradigm by classifying the intent of existing decision-making processes on the spectrum of approaches from planning theory 
3. Acknowledging the limitations of science, whilst valuing its role and embracing the democratic political decision-making approach. This may decrease the divide between the arts and sciences;

4. Considering the spectrum of approaches and how they define the ethic and intent of the professions;

5. Acknowledging incremental improvement in the knowledge-base of the decision-maker, thereby not losing sight of the importance of investing in sector-specific experienced practitioners;

6. Increasing awareness of the role of 'creativity' and 'consultation', with 'professional judgements' to be seen as valid and 'creativity' an asset rather than a substitute for precision;

7. Assisting planners to learn from resource managers about the benefits of tools and case-studies

8. Embedding information about fundamental theoretical differences in professional training at graduate and post-graduate levels; and

9. Developing clearer definitions and a shared understanding of different approaches, without losing the unique meanings ascribed by the professions.

An acceptance of a participatory-incremental hybrid framework for resource management may provide greater freedom for the profession, enabling accommodation of biophysical, social and economic sciences in a robust framework. Planners and public administrators have placed their profession towards the incremental end of the decision-making spectrum and are able to accommodate participatory approaches at this end. They view rigorous science as a means of informing incremental decision-making. A deviation away from striving to achieve optimality in individual decisions and providing acceptance of the incremental and participatory nature of past decisions may be refreshing. In fact, a softening away from optimality may assist to develop theory that better reflects and supports practice.

In no way do we contend that the effort on scientific excellence should be reduced, nor that decision-making should occur without regard to a full array of consequences. In fact, literature about scenario planning, optimisation and market knowledge could be further applied. Our key point is the need to be aware of the rational comprehensive origins of the profession and the resulting tensions that arise between what is espoused as best practice and the primarily participatory and incremental nature of resource management decisions when viewed retrospectively. Agreement is required about the fundamental theoretical basis for the profession, from which ongoing support can be provided through tools, techniques and approaches, which have rationalcomprehensive origins.

\section{Conclusions}

In delivering on the key objective of this paper, we have commenced the consideration of the classic form of incrementalism in the context of resource management, as Collingridge [15] achieved for medical and atomic sciences. We show how resource management tends to follow an incremental participatory hybrid model and whilst decisions are strongly informed by science, on reflection, the process of formulating decisions is rarely rational-comprehensive. We suggest greater retrospective analysis of resource management decisions at a theoretical level, with a transition in mindset supported by changes in emphasis in resource management education. This may result in adoption of a theoretical framework which better supports practice, a reduction in tensions between those trained in the arts and sciences and more 'freedom' in practice, through a softening of the focus on optimality. In conducting a 'second take' on the role of science, we highlight the view of planners that a democratic decision-making process is no more or less flawed than the 'problems of science'.

\section{Acknowledgements \\ Richard Cardew for introducing planning theory to resource management in New South Wales, Australia; Robert Brown for advising how to best present theory from two separate disciplines in a single paper; and Ashley Webb for a final critique and comment.}

\section{Authors' contributions}

Authors' contributions were by both authors of this work. Both authors read and approved the final manuscript.

\section{Funding}

Funding was not provided specifically for this work and the funding provided for the numerical work that it draws from is acknowledged in those publications. The organisations that allowed us to contribute time to this work are acknowledged by affiliation.

\section{Availability of data and materials}

Availability of data and material is not applicable, as the paper is theoretical, drawing on references to prior published work that is numerical in nature.

Ethics approval and consent to participate

Ethics approval and consent to participate was not applicable to this study, as it takes a theoretical approach, without human or animal subjects.

Consent for publication

Consent for publication is also not applicable, as the paper is theoretical.

Competing interests

Competing interests are not present.

Received: 19 March 2019 Accepted: 28 November 2019

Published online: 07 January 2020

\section{References}

1. Ampt $P$, Cross $R$, Ross $H$, Howie $B$. The case for retaining, redefining and reinvigorating extension in agricultural innovation systems. Rural Ext Innov Syst J. 2015;11(1):157-64.

2. Banks SA, Docker BB. Delivering environmental flows in the Murray-Darling basin (Australia) - legal and governance aspects. Hydrol Sci J. 2014;59(3-4): 688-99. https://doi.org/10.1080/02626667.2013.825723 T.

3. Briassoulis $\mathrm{H}$. Theoretical orientations in environmental planning: an inquiry into alternative approaches. Environ Manag. 1989;13(4):381-92. 
4. Brock PM. The significance of the Macquarie marshes physical environment. Aust Geogr. 1998;29(1):71-90.

5. Brock PM. Grazier and irrigator perceptions of management issues affecting the Macquarie marshes. Aust J Soil Water Conserv. 1996a;9(2):9-15.

6. Brock PM. Landholder views of the boundaries of the Macquarie marshes. Wetlands (Australia). 1996b;15(2):62-81.

7. Brock PM, Muir S, Herridge DF, Simmons A. Cradle-to-farm gate greenhouse gas emissions for 2-year wheat monoculture and break crop-wheat sequences in South-Eastern Australia. Crop Pasture Sci. 2016a;67(8):812-22. https://doi.org/10.1071/CP15260

8. Brock PM, Schwenke GD, Herridge DF. Assessing the greenhouse gas emissions mitigation potential for cereal-based cropping sequences through changes to management of synthetic and biologically-fixed N inputs. 2016b; Proceedings 10th International LCA Food Conference, Dublin, UK, 19-21 October

9. Brock PM, Graham P, Madden P, Alcock DJ. Greenhouse gas emissions profile for $1 \mathrm{~kg}$ of wool produced in the Yass Region, New South Wales: a life cycle assessment approach. Anim Prod Sci. 2013;53:495-508.

10. Brock P, Madden P, Schwenke G, Herridge D. Greenhouse gas emissions profile for 1 tonne of wheat produced in central zone (east) New South Wales: a life cycle assessment approach. Crop Pasture Sci. 2012;63(4):319-29.

11. Bruel A, Troussier N, Guillaume B, Sirina N. Considering ecosystem services in life cycle assessment to evaluate environmental externalities. Berlin: Proceedings 23rd CIRP Conference on Life Cycle Engineering; 2016. 22-24 May 2016, viewed 27 July 2017 <http://www.sciencedirect.com/science/ article/pii/S2212827116301147>

12. Cardew R. Two cultures, common purpose. Aust Plann. 1999:36(3):134-41.

13. Chalmers AF. What is this thing called science. St. Lucia: University of Queensland; 1990.

14. Cocks D. Use with care. Managing Australia's natural resources in the twenty first century. Kensington: New South Wales University Press; 1992.

15. Collingridge D. Incremental decision making in technological innovation: what role for science? Sci Technol Hum Values. 1989;14(2):141-62.

16. Cross R, Ampt P. Exploring Agroecological sustainability: unearthing innovators and documenting a Community of Practice in Southeast Australia. Soc Nat Resour. 2016;30(5):585-600.

17. Curran MA. Life cycle assessment handbook: a guide for environmental sustainable products. Hoboken: Wiley; 2012.

18. Dart JJ, Curnow M, Behrendt R, Kabore C, Oldham CM, Rose IJ, Thompson AN. The national lifetime wool project: a journey in evaluation. Anim Prod Sci. 2011;51:842-50.

19. Davidoff P. Advocacy and pluralism in planning. J Am Inst Plann. 1965;31: 331-8.

20. DeYoung DJ, Conner RF. Evaluator preconceptions about organizational decision making. Rational versus incremental perspectives. Eval Rev. 1982; 6(3):431-40

21. Encyclopædia Britannica. Natural resource management. 2019 [https:/www. britannica.com/topic/natural-resource-management]. Date accessed: Nov 21, 2019.

22. Etzioni A. Mixed-scanning: a 'third' approach to decision-making. Public Adm Rev. 1967;27(5)385-392.

23. European Commission, Joint Research Centre, Institute for Environment and Sustainability. International Reference Life Cycle Data System (ILCD) handbook - general guide for life cycle assessment - detailed guidance. Luxembourg: Publications Office of the European Union; 2010. First edition March 2010. EUR 24708 EN

24. Flysjö AM, Cederberg C, Henriksson M, Ledgard S. How does co-product handling affect the carbon footprint of milk? Case study of milk production in New Zealand and Sweden. Int J Life Cycle Assess. 2011;16(5):420-30.

25. Friedmann J. The use of planning theory. A bibliographic essay. J Plan Educ Res. 2008;28:247-57.

26. Gale R, Brock P, Milham N. Assessing the contribution of investment in natural resource management to economic sustainability and social wellbeing. Orange: Industry and Investment; 2010. Technical Report 12. Monitoring, Evaluation and Reporting Program. Technical Report Series. June 2010

27. Guo M, ChangSheng L, Nigel J, Bell B, Murphy RJ. Influence of agroecosystem modelling approach on the greenhouse gas profiles of wheatderived biopolymer products. Environ Sci Technol. 2012;46(1):320-30.

28. Grant T, Beer T. Life cycle assessment of greenhouse gas emissions from irrigated maize and their significance in the value chain. Aust J Exp Agric. 2008:48:375-81.
29. Haasnoot M, Kwakkel JH, Walker WE, ter Maat J. Dynamic adaptive policy pathways: a method for crafting robust decisions for a deeply uncertain world. Glob Environ Chang. 2013;23:485-98.

30. Hammond KR, Mumpower J, Dennis RL, Fitch S \& Crumpacker W. Fundamental Obstacles to the Use of Scientific Information in Public Policy Making. Technological Forecasting and Social Change 1983; 24: 287-297.

31. Healey P. Planning through debate: the communicative turn in planning theory. Town Plan Rev. 1992;63(2):143-61.

32. Hedayati M, Brock PM, Simmons AT. How sensitive is the calculated climate change impact of cotton production in North West New South Wales to fertiliser-related $\mathrm{N}_{2} \mathrm{O}$ emission values? Melbourne: Proceedings 1st Australian Conference on Life Cycle Assessment for Agriculture and Food; 2015a. 23-24 Nov

33. Hedayati M, Brock PM, Simmons AT. Consequential LCA in cotton production systems: opportunities. Melbourne: Proceedings 1st Australian Conference on Life Cycle Assessment for Agriculture and Food; 2015b. 23-24 Nov

34. Hedayati M, Brock P, Nachimuthu G, Schwenke G. Farm-level strategies to reduce the life cycle greenhouse gas emissions of cotton production: An Australian perspective. Journal of Cleaner Production 2018; 212:974-985. https://doi.org/10.1016/j.jclepro.2018.11.190

35. Herridge DF, Brock PM. Annual crop legumes may not mitigate greenhouse gas emissions because of the high carbon cost of nitrogen fixation. Melbourne: Proceedings 2016 International Nitrogen Initiative Conference, 'Solutions to improve nitrogen use efficiency for the world'; 2016. 4-8 Dec, < www.ini2016.com>

36. Horne R, Grant T, Verghese K. Life cycle assessment-principles, practices and prospects. Melbourne: CSIRO Publishing; 2009.

37. Hudson BM. Comparison of current planning theories: counterparts and contradictions. J Am Plan Assoc. 1979:45:387-98.

38. Ingram JSI. A food systems approach to researching interactions between food security and global environmental change. Food Secur. 2011;3:417-31.

39. Ingram J. Scientific keynote: UNEP sustainable food systems report. Dublin: Proceedings 10th International Conference on Life Cycle Assessment of Food 2016; 2016. 19-21 Oct

40. ISO (International Organization for Standardization). Greenhouse gases carbon footprints of products - requirements and guidelines for quantification and communication, 2013 ISO/TS 14067: viewed 15 January 2016 <http://www.iso.org/iso/catalogue_detail?csnumber=59521>.

41. Ison RL, Ampt PR. Rapid rural appraisal: a participatory problem formulation method relevant to Australian agriculture. Agric Syst. 1992;38:363-86.

42. Klosterman RE. Arguments for and against planning. Town Plan Rev. 1985; 56(1):5-20.

43. Lindblom C. The Science of Muddling through. Public Administration Review. 1959; 29: 151-169.

44. Lindblom C. Still muddling, not yet through. Public Adm Rev. 1979;39(6): $517-26$.

45. Mant J. The Instruments of Planning, Urban Research Unit Working Paper No. 6, Urban Research Unit ANU, Canberra. 1988; pp. 17-35.

46. McManus MC, Taylor CM, Mohr A, Whittaker C, Scown CD, Borrion AL, Glithero NJ, Yin Y. Challenge clusters facing LCA in environmental decisionmaking — what we can learn from biofuels. Int J Life Cycle Assess. 2015;20: 1399-414.

47. Neutze M. Urban planning, policy and management. In: McLoughlin JB, Huxley M, editors. Urban planning in Australia: Critical readings. Melbourne: Longman Cheshire; 1986. p. 871-101.

48. Noguera-Mendeza P, Molerab L, Semitiel-Garciaa M. The role of social learning in fostering farmers' pro-environmental values and intentions. $J$ Rural Stud. 2016:46:81-92. https://doi.org/10.1016/j.jurstud.2016.06.003.

49. Paterson J. Co-ordination in government: decomposition and bounded rationality as a framework for use friendly statue law. Aust J Public Adm. 1986:45(2):95-111.

50. Plevin RJ, Dleucchi MA, Creutzig F. Using Attributional life cycle assessment to estimate climate-change mitigation benefits misleads policy makers. J Ind Ecol. 2013;18(1):73-83.

51. Ratliffe J. An introduction to town and country planning. London: Hutchinson; 1974. p. 3-24.

52. Schwartz MW, Cook CN, Pressey RL, Pullin AS, Runge MC, Salafsky N, Sutherland WJ, Williamson MA. Decision support frameworks and tools for conservation review. Conserv Lett. 2018;11(2):1-12. https://doi.org/10.1111/ conl.12385 
53. Slocombe DS. Environmental planning, ecosystem science, and ecosystem approaches for integrating environment and development. Environ Manag. 1993;17(3):289-303.

54. Suenaga $H$, Tan DKY, Brock PM. Life-cycle assessment of rice production systems: Comparison of Lao PDR, Japan and Australia. Wellington: Proceedings 3rd LCANZ and NZLCM Centre Life Cycle Assessment Conference; 2014. 2-3 Sept

55. Termeer CJAM, Dewulf A, Biesbroek GR. Transformational change: governance interventions for climate change adaptation from a continuous change perspective. J Environ Plan Manag. 2017;60(4):558-76.

56. Vervoort JM, Thornton PK, Kristjanson P, Förch W, Ericksen PJ, Kok K, Ingram JSI, Herrero M, Palazzo A, Helfgott AE, Wilkinson A, Havl''k P, Mason-D'Croz $D$, Jost C. Challenges to scenario-guided adaptive action on food security under climate change. Glob Environ Chang. 2014;28:383-94.

57. Weidema BP. The social footprint-a practical approach to comprehensive and consistent social LCA. Int J Life Cycle Assess. 2016;21:700-709. https:// doi.org/10.1007/s11367-016-1172-z.

58. Whittenmore $\mathrm{AH}$. Practitioners theorize, too: reaffirming planning theory in a survey of practitioners' theories. J Plan Educ Res. 2015;35(1):76-85.

59. Wildavsky A. If planning is anything, perhaps it is nothing. Int Rev Adm Sci. 1973:32(1):127-54

\section{Publisher's Note}

Springer Nature remains neutral with regard to jurisdictional claims in published maps and institutional affiliations.

Ready to submit your research? Choose BMC and benefit from:

- fast, convenient online submission

- thorough peer review by experienced researchers in your field

- rapid publication on acceptance

- support for research data, including large and complex data types

- gold Open Access which fosters wider collaboration and increased citations

- maximum visibility for your research: over $100 \mathrm{M}$ website views per year

At $\mathrm{BMC}$, research is always in progress.

Learn more biomedcentral.com/submissions 